\title{
Artigos
}

\section{O que pode a escola pública diante das desigualdades?}

\section{What can the public school before inequalities?}

\author{
Maria Isabel de Almeida' (iD 0000-0003-2506-2972 \\ Cláudia Dourado de Salces² (iD 0000-0003-1582-3766 \\ Tiago Rufino Fernandes ${ }^{3}$ (D) 0000-0002-3929-3125
}

\section{Resumo}

Este artigo objetiva problematizar a função social da escola pública no enfrentamento da desigualdade, compreendida como uma categoria estrutural para o entendimento da sociedade brasileira e possuidora de expressões em diferentes campos, razão pela qual se caracteriza como sendo de natureza multideterminada. Sua existência e permanência foram abordadas em uma de suas formas fundamentais - a educacional -, elencando-se as desigualdades educativas no escopo da desigualdade como marcador estrutural. Realizou-se um breve percurso histórico do papel da escola pública, evidenciando como os modos de escolarização possuem

1 Universidade de São Paulo, Faculdade de Educação, Departamento de Metodologia do Ensino e Educação Comparada. Av. da Universidade, 308, Butantã, 05508-040, São Paulo, SP, Brasil. Correspondência para/Correspondence to: M.I. ALMEIDA.E-mail:<mialmei@usp.br>.

2 Prefeitura Municipal de Valinhos, Secretaria da Educação. Valinhos, SP, Brasil.

3 Prefeitura Municipal de Guarulhos, Secretaria da Educação. Guarulhos, SP, Brasil.

Como citar este artigo/How to cite this article

Almeida, M. I.; Salces, C. D.; Fernandes, T. R. O que pode a escola pública diante das desigualdades? Revista de Educação PUC-Campinas, v. 26, e215328, 2021. https://doi.org/10.24220/23180870v26e2021a5328

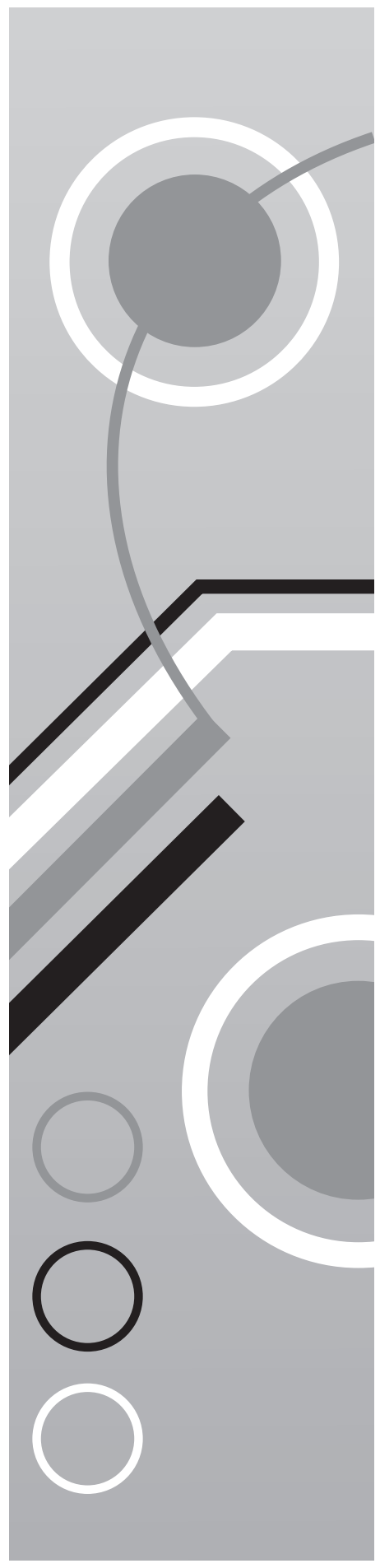


uma relação direta e explícita com políticas educacionais forjadas nacional e internacionalmente, além de destacar os desafios que permitem formular um diagnóstico do quadro histórico atual em matéria educativa. Evidenciou-se que a desigualdade escolar, atrelada a um projeto político, além de ser o resultado da ineficácia das políticas públicas, é, também, o produto dessas. Em face dessas contingências, foram aventados alguns desdobramentos responsivos da escola em face, sobretudo, do currículo e da formação de professores. Em termos metodológicos, trata-se de uma pesquisa bibliográfica de caráter conceitual, que problematiza a desigualdade como conceito multidimensional. A referência teórica, embasada em uma perspectiva crítico-transformadora, com o auxílio de uma sociologia crítica, buscou uma aproximação com orientações que vislumbram a superação das desigualdades escolares.

Palavras-chave: Conhecimento poderoso. Desigualdades. Direito à educação. Emancipação. Escola pública.

\begin{abstract}
This paper aims to problematize the social role of public schools in confronting inequality, understood as a structural category for reflection on Brazilian society, with expressions in different fields, reason why it is characterized as having a multi-determined nature. The existence and permanence of inequality were discussed in one of its fundamental forms - the educational one -, listing educational inequalities in the scope of inequality as a structural marker. A brief historical overview of the role of the public school was carried out, showing how the modes of schooling have a direct and explicit relationship with educational policies forged nationally and internationally, in addition to highlighting the challenges that allow the formulation of a diagnosis of the current historical framework in educational matters. It is evident that school inequality, combined with a political project is not only the result of the ineffectiveness of public policies, but also their product. In view of these contingencies, some responsive appointments of the school were suggested, especially regarding the curriculum and teacher training. In methodological terms, this is a conceptual bibliographic research, which discusses inequality as a multidimensional concept. The theoretical reference, based on a critical-transformative perspective, with the aid of a critical sociology, sought an approximation with guidelines that aimed to overcome school inequalities.
\end{abstract}

Keywords: Powerful knowledge. Inequality. Right to education. Emancipation. Public school.

\title{
Introdução
}

A grandeza de um homem se define por sua imaginação. E sem uma educação de primeira qualidade, a imaginação é pobre e incapaz de dar ao homem instrumentos para transformar o mundo

(Florestan Fernandes)

Uma pergunta disparadora orienta as reflexões deste artigo: o que pode fazer a escola pública no enfrentamento das desigualdades que assolam nosso país e vitimizam parcelas significativas da população, especialmente as crianças e jovens em idade escolar? É claro que essa questão engendra inúmeras outras, como: quais os compromissos históricos da escola pública com a totalidade das populações e como esses compromissos transformaram-se com o tempo, tornando distante o ideal de 
escola pública para todos? Como as desigualdades sociais permeiam os modos de escolarização no país evidenciando uma relação direta e explícita com políticas educacionais direcionadas ao atendimento de interesses de grupos econômica e politicamente hegemônicos? O que fazer frente às investidas cada vez mais violentas contra a escola pública, especialmente nos campos do currículo e da formação dos professores?

Essas perguntas, decorrentes de um quadro amplo de produção de desigualdade com expressões na economia, na cultura e na educação, exigem uma abordagem do próprio conceito de desigualdade como uma categoria plural. Ao longo deste artigo, serão usados os termos "desigualdade" e "desigualdades". Essa alternância significa apenas uma tentativa de capturar as nuanças da palavra em sua complexidade empírica e teórica.

Para fins argumentativos, a desigualdade é compreendida como uma categoria estrutural para o entendimento da sociedade brasileira, com expressões em diferentes campos, razão pela qual possui uma característica multideterminada. Neste texto, sua existência e sua permanência serão abordadas em uma de suas formas fundamentais: a educacional. Assim, procura-se relacionar as desigualdades educativas como conteúdo da desigualdade como marcador estrutural.

Inicialmente, trata-se do papel da escola pública na história e, para isso, são levantados os desafios que permitem formular um diagnóstico do quadro histórico vivenciado em matéria educativa. Em seguida, a noção de desigualdade escolar como um projeto político é discutida, não só como resultado da ineficácia das políticas públicas, mas justamente como produto dessas. Por fim, alguns dos desdobramentos responsivos da escola em face, sobretudo, do currículo e da formação de professores, são abordados.

Em termos metodológicos, trata-se de uma pesquisa bibliográfica de caráter conceitual, realizada com fins de problematização da desigualdade como conceito multidimensional. Dada a complexidade do fenômeno, optou-se por trabalhar com referências organizadas em torno do universo teórico crítico que permitam uma abordagem, de um lado, do ponto de vista histórico-sociológico e, de outro, do ponto de vista político-pedagógico.

\section{O papel da escola pública e seus desafios emergentes}

A escola pública, desde a sua constituição como instituição estatal e pública na Europa do século XIX, sempre foi objeto de disputas que se traduziram em projetos reformadores para recompor os interesses da classe dominante, que se sentia ameaçada pelas pressões políticas das massas. Desde a metade do século XX, organismos e conferências multilaterais têm buscado estabelecer diretrizes para as políticas públicas educacionais, especialmente para os chamados "países em desenvolvimento", e têm tido bastante êxito.

Esses projetos reformadores ganharam contornos mais agressivos nos últimos 50 anos com as imposições do chamado 'mercado'em dupla direção. Por um lado, o capital financeiro busca controlar o aparato escolar, bem como todos os serviços que lhe são essenciais, por meio de políticas favorecedoras da privatização da educação. Por outro lado, os interesses capitalistas hegemônicos têm conseguido direcionar as orientações da ação educacional, como currículo, avaliação e organização da atuação 
pedagógica, por meio da ocupação dos espaços definidores das políticas educacionais nos órgãos estatais das três esferas administrativas. No caso brasileiro, há um grande esforço empenhado na despolitização e no esquecimento das lutas populares que historicamente engendraram essa instituição, facilitando aquilo que Carvalho (2020) chama de um 'passado vazio', favorecedor de reformas nefastas.

\section{Fios condutores da história da escola pública}

No mundo ocidental moderno, a escola pública estatal ganhou centralidade como o lugar onde se desenvolve a educação. Como qualquer instituição social, ela é um construto histórico, marcado pelas contradições e disputas presentes na sociedade. Mas como o Estado constituiu as forças necessárias para fazer com que a sociedade lhe delegasse a educação de seus filhos por meio da ação da escola pública?

Sua origem se deu em meio às transformações vividas pela Europa, decorrentes de acontecimentos econômicos, urbanos, religiosos, políticos, ideológicos e culturais. A retomada do comércio e o renascer da vida urbana fizeram com que a sociedade se reconfigurasse, distanciando-se das relações medievais e provocando mudanças no processo de escolarização. Assim, em sintonia com as transformações em curso, a escola foi sendo organizada no sentido de orientar o fazer dos mestres-escolas com método e ordem nos processos de ensino e aprendizado. Segundo Hamilton (2001, p. 51), foram esses procedimentos"que conferiram identidade cultural tanto à escolarização moderna quanto à sociedade europeia moderna".

Essa mudança trouxe contribuições para a reconfiguração da política e a ascensão do Estado Moderno sustentado por novas formas jurídicas, políticas, religiosas, artísticas, filosóficas e educativas. A escola pública se constituiu como um construto moderno e sedimentador de um novo modo de organização social, econômico e político. Hamilton (2001, p. 48) chega a afirmar que "a escolarização moderna não teve ancestrais institucionais". A Revolução Francesa representou o momento e o lugar de uma nova estrutura organizadora do sistema educativo moderno, fornecendo o exemplo dos "fundamentos para a escola contemporânea, com seu caráter estatal, centralizado, organicamente articulado, unificado por horários, programas e livros de texto"(Cambi, 1999, p. 365). Também se instituiu a separação dos estudantes por níveis de aprendizado e idade, controle de presença e divisão por matérias, tendo como objetivo aumentar o controle dos mestres sobre os alunos.

Mas, para além da linearidade desse percurso, é possível identificar alguns outros elementos dessas transformações, como propõe Veiga (2002). Para ela, a ideia de modernização da sociedade a partir da organização dos estados modernos passou por um processo de racionalização que afeta as mentalidades e o dispositivo social, e envolveu o monopólio estatal das técnicas e dos saberes necessários à implementação do projeto civilizador e à incorporação dos pobres na sociedade civilizada. Tem-se então uma nova perspectiva cultural instaurada nesse contexto - a do caráter "civilizado" que a sociedade europeia passa a construir como referência de si própria, simultaneamente à instauração do sistema capitalista. Esse novo ideal apoia-se na transformação de "uma nação turbulenta em um povo pacífico, perigoso apenas para seus inimigos. Tal concepção de civilização é tomada como um programa de reforma que iria culminar, no século XIX, na autoimagem dos países europeus em relação a outras sociedades que Ihes cabia civilizar" (Veiga, 2002, p. 96). 
O Estado passa a trazer para sua reponsabilidade a construção da instituição escolar em decorrência da expansão capitalista e sua onda 'civilizatória', cujos resultados exterminadores são sobejamente conhecidos em três continentes. Portanto, é em decorrência desse novo projeto político-econômicocivilizatório que os pobres foram incorporados à sociedade civilizada e que a escola pública deu sua contribuição para uma nova configuração de sociedade por meio da homogeneização cultural, base para uma nova visão de mundo.

Essa escola pública, que incluiu os pobres num projeto civilizador, o fez com base na homogeneização das relações de gênero, com a diferenciação de infância e adolescência e a produção dos modelos de criança inteligente e jovem bem-comportado, e na socialização de uma perspectiva branqueada de cultura, processo permeado pelos valores de sucesso, competitividade e meritocracia (Veiga, 2002). Esse processo homogeneizador de valores e comportamentos, capitaneado pelo Estado, valeu-se muito das (re)configurações de tempo, espaço, métodos, manuais, disciplinas e controle comportamental, dentre outros fatores. Processou-se, assim, uma inclusão que, ao mesmo tempo em que incluía, também diferenciava, o que era fundamental para a sociedade de classes. Nascia o liberalismo como ideologia e se estabelecia uma relação direta entre educação e cidadania.

Enfim, essa escola nascente foi contemporânea de um rol de transformações que ocuparam todo o século XIX. Com as origens fincadas no seio da Revolução de 1789, acompanhou o movimento que permitiu à ordem burguesa se tornar triunfante sobre os resquícios do Antigo Regime e também sobre as novíssimas ideias socialistas, que deram seus primeiros sinais na disputa política na Comuna de Paris em 1871. A hegemonia burguesa, lastreada no capitalismo, consolidou a democracia como regime político baseado na soberania popular, o que pressupõe a necessidade de ser educado para participar de movimentos sociais e políticos. Com isso, foi atribuída à escola uma função eminentemente política.

À medida que os trabalhadores tiveram seu lugar reposicionado no seio das forças produtivas e foram chamados a participar do jogo político institucional, afloraram as contradições irreconciliáveis de classe. No entanto, foi apenas no século XX que a educação passou a ser compreendida como partícipe e impulsionadora do enfrentamento das desigualdades econômicas e sociais. Com isso, as disputas de projetos educacionais distintos constituíram-se como marca do século XX e se fizeram presentes nas duas primeiras décadas do século XXI.

\section{Como o projeto civilizatório da modernidade se 'abrasileirou'?}

Assim como foi visto na breve retrospectiva da história da escola no contexto europeu, no Brasil, as medidas destinadas à constituição de um aparato capaz de assegurar os processos educativos à população do país também guardam relação com os interesses dos grupos sociais hegemônicos, orientadores da organização e da ação do Estado. Porém, enquanto na Europa a educação vinculouse à esfera da ação estatal por meio de políticas públicas, com caráter cívico e entendida como direito social, aqui, passados cinco séculos, ainda enfrentam-se dilemas relativos à efetivação da garantia do direito à educação.

Com a chegada dos colonizadores portugueses, vieram os jesuítas com a "missão civilizadora e educacional" de escolarizar os filhos dos colonos portugueses e integrar os indígenas ao mundo cristão 
por meio da catequese, o que pressupunha a desarticulação cultural dos nativos por meio do ensino da leitura, da escrita e do cálculo. Iniciaram-se, assim, os rudimentos de uma educação sustentada nos objetivos da evangelização e da pacificação, fundamentais para facilitar a ocupação e a exploração colonial do território - uma empreitada implementada pelo Estado e Igreja irmanados. Somente com a vinda da família real portuguesa, em 1808, é que os procedimentos educacionais avançaram da escola bastante rudimentar de primeiras letras para um patamar de formação técnica, com alguns cursos superiores voltados para uma parcela muito restrita da população. Longe dos arranjos que deram sustentação ao Estado liberal europeu e asseguraram aos países a constituição de um sistema nacional de educação no século XIX, aqui, as elites brasileiras, partícipes da mentalidade colonizadora e escravocrata, atuavam na direção de preservar seus interesses econômicos, políticos e sociais, sem compromissos com a coletividade.

Na década de 1930, com o início da transição da economia predominantemente agrária para uma parcialmente industrializada e com mudanças na máquina estatal que requisitaram a atuação de um corpo burocrático maior e mais preparado, foi criado o Ministério da Educação e Saúde, explicitando o entendimento da educação como questão nacional. Os movimentos em prol de uma educação estatal, reconhecida como direito e com normatização específica, acabou dando passos pouco contundentes, uma vez que o Estado brasileiro, longe de se preocupar com a distribuição de renda e o provimento do bem-estar social da população, centrou seus esforços na transição de uma economia eminentemente agrária para uma industrial.

Nas duas décadas seguintes, apesar dos apelos à ideia de atendimento dos anseios populares e de uma marca nacionalista nas ações do Estado, pouco se avançou no terreno educativo. Com a chegada dos militares ao poder em meados dos anos de 1960, consolidou-se uma política centralizadora que promoveu a abertura do país ao capital estrangeiro. No campo educacional, houve a promulgação de uma reforma universitária, gerando reação veemente do movimento estudantil - prontamente reprimida - e a reformulação do ensino de $1^{\circ}$ e $2^{\circ}$ graus. Ambas as reformas foram marcadas por um caráter tecnocrático e voltadas para assegurar o controle social por meio da educação. Somente nos anos de 1980, com as mudanças internacionais e a resistência à ditadura militar, essa configuração do Estado foi politicamente transformada. Porém, o país foi envolvido nas garras da nova configuração internacional do capitalismo, denominada de neoliberalismo, agravando os efeitos decorrentes dos cinco séculos de herança colonial-escravocrata-aristocrática.

Segundo dados da Instituto Brasileiro de Geografia e Estatística (2019), o Brasil tem, hoje, cerca de 11 milhões de pessoas analfabetas, o que expressa o pouco empenho político no atendimento das demandas escolares da população como um todo. Nas palavras de Pinto (2006, p. 67):

em qualquer um dos diferentes momentos políticos da história recente do país em que a universalização do Ensino Fundamental vem se efetivando, ela ocorre acompanhada por uma série de precariedades decorrentes, em sua maioria, pela falta de investimento financeiro suficiente na área.

A partir dos anos de 1990, as políticas educacionais foram marcadas por uma ambiguidade entre o discurso que reconhece a importância da educação e as políticas promotoras da redução dos investimentos na área, preparando a ação dos negócios educacionais. É o que Lombardi e Colares 
(2020) consideram como o primado da "racionalidade financeira" no setor, com o predomínio do capital financeiro internacional. A educação deixa de ser um direito e uma obrigação do Estado, passando a integrar o setor de "comércio de serviços", direcionado ao atendimento das demandas internacionais e aos interesses do mercado de trabalho.

Esse movimento redireciona as políticas educacionais brasileiras de modo a adequar o ensino e as práticas docentes aos ditames do capital financeiro globalizado. Com isso, os ideais de uma escola pública, laica, obrigatória e gratuita, defendida no Manifesto dos Pioneiros da Escola Nova em 1932, pelos movimentos sociais e novamente expressos na Lei de Diretrizes e Bases da Educação Nacional (no 9394/1996), ficam relegados às calendas gregas. A privatização e as políticas uniformizadoras do currículo, da avaliação, da organização da escola e do trabalho docente, e da formação de professores tornam cada dia mais difícil e distante a consubstanciação do desejo de Florestan Fernandes ao manifestar a importância de uma educação de primeira qualidade para a transformação do mundo em prol das maiorias que vivem cotidianamente os horrores da desigualdade estrutural do Brasil ao longo de toda a sua história.

\section{As desigualdades como processos sociais intencionalmente construídos}

Com base no cenário acima reconstruído, parte-se do pressuposto de que a desigualdade se mostra no conjunto de produções sociais com base em fatores diversos que envolvem a distribuição da riqueza, o acesso a direitos e o reconhecimento das identidades, citando apenas alguns. Trata-se de um conceito multidimensional que precisa ser visto no contexto da multiplicidade de expressões econômicas, sociais, culturais e políticas. Portanto, a desigualdade apresenta diferentes faces, diferentes formas de expressão nas sociedades modernas.

As disparidades de acesso, que selam destinos e limitam a mobilidade social dos cidadãos, perenizam uma situação de reprodução social no quadro das sociedades democráticas, as quais se fundamentam em princípios igualitários de justiça social. Essas injustiças são assim percebidas porque são produções institucionais, derivadas das medidas políticas com implicações objetivas na vida dos cidadãos, distorcendo o próprio princípio democrático.

Dessa maneira, escusando-se o truísmo, as desigualdades sociais não são naturais; isto é, não são decorrentes de uma condição inerente à existência do ser humano fora das instituições sociais e das relações políticas concretas. Entender o processo de produção social da desigualdade torna-se um dos maiores desafios para o entendimento do papel e dos compromissos da escola pública no processo educacional.

Para tanto, a fim de caracterizar a desigualdade educacional de modo que seja possível tensionar os sentidos e as práticas no campo educativo, reconstruiu-se um debate sobre as desigualdades com foco nesse campo, articulando-o a diretrizes políticas forjadas internacionalmente, as quais não têm favorecido a superação do quadro de injustiça socialmente produzido na oferta educativa, em especial para os mais pobres. Envida-se, assim, um esforço de problematização a fim de que sejam criadas condições para a superação do caráter reprodutor da escola na sociedade. 


\section{Desigualdade escolar como conceito e projeto político}

O tema da desigualdade social é um dos mais estruturais para entender a sociedade brasileira. Para analisá-la no campo da educação, com recurso a Coleman (2011) e Bourdieu (2007, 2013), chegando a Dubet $(2004,2008)$ e Crahay (2013), pode-se reconstruir um quadro de desigualdade estrutural que impede o alcance do princípio da igualdade de oportunidades e mantém a reprodução social, inviabilizando a construção de patamares maiores de justiça educativa.

Adentrando o ponto central da argumentação deste artigo, referencia-se mais detidamente Bourdieu (2007), cuja compreensão concebe a escola como uma instituição com tendência à reprodução e conservação social. Não obstante sua promessa de mobilidade, a manutenção das estruturas sociais confere legitimidade às desigualdades sistemática e institucionalmente produzidas.

Um dado fundamental das consequências da desigualdade, ou mesmo de sua existência como estrutura, é o fato de haver uma homologia entre posição social e escolhas educativas, as quais definem o destino de parcelas significativas dos indivíduos. O caráter subjetivo da escolha, nessa perspectiva, parece ser a expressão de estruturas objetivas de distribuição das oportunidades sociais, posto que:

a estrutura das oportunidades objetivas de ascensão social, e, mais precisamente, das oportunidades de ascensão pela escola condicionam as atitudes frente à escola e à ascensão pela escola [...] e isso por intermédio de esperanças subjetivas [...], que não são senão as oportunidades objetivas intuitivamente apreendidas e progressivamente interiorizadas (Bourdieu, 2007, p. 49).

A citação acima permite salientar que as escolhas são produtos sociais derivados de elementos objetivos presentes na estrutura das oportunidades. A desigualdade incide não só no acesso às posições, mas também nas aspirações dos indivíduos ao longo da sua vida, tendo efeitos subjetivos de consequências duradouras.

Combater a estrutura objetiva das desigualdades permite o enfrentamento de questões voltadas às expectativas que os indivíduos possuem com relação ao sistema escolar e às oportunidades sociais em sentido mais amplo. Daí a importância, na esteira de Bourdieu e Champagne (2007), de combater os distintos padrões de exclusão que se expressam pelo tipo de ensino oferecido pela escola ou pela desvalorização dos diplomas.

Esse padrão de exclusão, mutatis mutandis, pode ser visto na escola pública brasileira sob a forma de um "dualismo perverso" (Libâneo, 2012). Essa é uma das faces visíveis de um sistema que relega uma parte dos atendidos a um destino social subalterno, ao passo que a outra parte pode organizar suas escolhas conforme uma posição mais vantajosa no interior da estrutura de oportunidades escolares.

Com efeito, o agravamento do dualismo de uma escola do conhecimento ou do acolhimento ressoa nas orientações políticas como, por um lado, uma escola voltada para os pobres e, por outro, uma instituição voltada para os ricos. Obviamente, a declaração de intenções passa pela aquisição do "conhecimento poderoso" (Young, 2007) por todos os estudantes, mas a estruturação do sistema pereniza a exclusão e a reprodução social.

Os padrões de qualidade da educação conferem determinados sentidos de qualidade às práticas educativas, referenciando o que significa ser uma escola com parâmetros de justiça socialmente aceitos. 
Portanto, o que é qualidade em educação também se apresenta como motivo de disputa e determina os compromissos educacionais das políticas públicas. No contexto dos organismos internacionais, que constituem nível macroestrutural de determinação, assim se expressam Libâneo e Freitas (2018, p. 24) "ao aplicar às escolas critérios de qualidade de ensino de cunho utilitário estabelecidos pelos organismos internacionais, a política educacional vem provocando a acentuação das desigualdades sociais produzindo a exclusão social dos pobres dentro da própria escola".

Nesse contexto, também emergem os sentidos de "justiça" das políticas chamadas meritocráticas, as quais legitimam desigualdades arbitrárias sob a valorização da competitividade (Libâneo, 2018). Seu sentido de qualidade educacional promove os valores de exclusão que se expressam na conquista e no sucesso entendidos como esforço individual, abstraído de qualquer característica social interferente. Isso porque a "meritocracia é vista pelos seus defensores como um procedimento justo porque avalia os méritos de cada um independentemente de características individuais, sociais e culturais" (Libâneo, 2018, p. 74). O problema desse pressuposto, entre outros, está no fato de que as desigualdades não ocorrem apenas dentro da escola, como fenômeno apartado da "sociedade", mas são justamente a expressão das desvantagens de ordem social, econômica e cultural. Por isso, o padrão meritocrático acaba por transformar a origem social em destino.

No bojo dessa concepção estão as políticas de bonificação e desempenho, as quais afirmam reconhecer o mérito. No entanto, pelo que se apresentou acima, embora se formulem pelo pressuposto de reconhecimento do esforço individual ou mesmo de um grupo escolar, essas políticas tendem a produzir distorções no sistema de garantias de direitos à medida que transferem ao campo dos bens sociais a lógica da concorrência que caracteriza as instituições e as relações de mercado.

Em síntese, essas políticas permitem a constatação de algo que, de modo difuso, está no senso comum, a propósito do sentimento de injustiça sobre a desigualdade escolar: a escola brasileira é desigual, além do fato de que no interior da desigualdade se esconde um dualismo de largo espectro, incapaz de promover o acesso a um conhecimento que emancipa e cria possibilidades de compreensão crítica da realidade.

\section{O caso brasileiro na lupa de Darcy Ribeiro e Florestan Fernandes}

Retomando o sentido de abrasileiramento do projeto civilizatório europeu, agora na chave da concepção de desigualdade acima formulada, retoma-se brevemente Darcy Ribeiro que, em conhecida comunicação na Sociedade Brasileira para o Progresso da Ciência em 1977, analisa criticamente o fracasso brasileiro em matéria de educação, apontando que o que o país vive como uma crise educacional é uma produção intencional. O autor se pronuncia nos seguintes termos: "[...] a crise educacional do Brasil da qual tanto se fala, não é uma crise, é um programa. Um programa em curso, cujos frutos, amanhã, falarão por si mesmos" (Ribeiro, 2019, p. 55).

Chegou-se ao amanhã e não se pode dizer que o projeto não foi bem-sucedido; ao contrário, sofisticou-se e penetrou até mesmo as concepções das políticas públicas, formuladas sem a consideração da necessária radicalidade democrática. Apesar de melhoras conjunturais, a estrutura educativa no Brasil ainda produz diferentes formas de desigualdade e as oportunidades de acesso igualitário e qualitativo 
à educação permanecem mal distribuídas. Dada essa "obviedade" educacional, é fundamental envidar esforços de mudança no interior de uma ordem social produtora de injustiça e marcada por determinações diversas. É nesse ponto que o debate de Fernandes (1966), já na década de 1960, se mostra ainda atual e ajuda a vislumbrar caminhos de transformação da escola pública.

Para o sociólogo, apesar da promessa da escola moderna no que se refere ao favorecimento do progresso civilizatório, a definição do poder da educação escolarizada ainda residia em uma disputa entre, de um lado, aqueles que viam na escola um fator de mudança social e, de outro, aqueles que viam na escola uma expressão da mudança produzida alhures (Fernandes, 1966). Para Fernandes, essas duas concepções se complementam e cada uma será mais enfatizada conforme a sociedade em que a educação se insere.

O que está no fundo do debate travado pelo sociólogo são a função social da escola e seus compromissos em face das finalidades políticas e sociais mais amplas. Isso significa dizer que a escola exerce influência na conformação da estrutura social em que se encontra, embora não se possa dizer que essa influência seja absoluta. No caso da desigualdade, ainda permanece a dificuldade de construir uma escola adequada aos interesses de desenvolvimento da sociedade brasileira:

O nosso sistema escolar ainda se organiza sob o imperativo de servir a tendências predominantemente conservantistas, mobilizando apenas uma fração dos recursos educacionais do ambiente: aquela que se relaciona com a necessidade de preservar a ordem estabelecida e, com ela, a posição que já conquistamos na fruição dos bens daquela civilização (Fernandes, 1966, p. 86).

Isso ocorre, entre outras coisas, porque não teria sido possível alcançar a "formação de um novo horizonte cultural, capaz de remodelar a capacidade de percepção, de explicação e de intervenção na realidade dos agentes humanos"(Fernandes, 1966, p. 89). Com essa característica, a mudança educacional e a superação da desigualdade carecem de vigor e de projeto e as influências dessa situação se fazem sentir em todos os setores, pois se a desigualdade, por um lado, mantém inalteradas as posições sociais e os privilégios dos já detentores de poder político e econômico, por outro, obstaculiza o desenvolvimento social de caráter democrático e redistributivo que poderia beneficiar o conjunto da população.

É nesse sentido que o sociólogo paulista assevera em sua análise: "O essencial é que se entenda que não há nem crescimento econômico, nem desenvolvimento social nem progresso cultural sem uma paralela integração das escolas nos processos de mudança social" (Fernandes, 1966, p. 95, grifos do autor). É em direção a essa "integração das escolas", no processo de mudança, que serão abordados abaixo alguns dos desdobramentos responsivos da escola pública na sociedade brasileira.

\section{Desdobramentos responsivos dos atores da escola pública}

Conforme explicitado nas seções precedentes, ao realizar uma análise histórica e sociológica dos percalços da escola pública, viu-se como o pensamento hegemônico sobre as funções da escola, assentado nos organismos internacionais, direciona as políticas educacionais. A agenda dessas instituições afeta não só instâncias decisórias relativas às políticas de financiamento, de definição de 
currículo, de formação de professores, de organização escolar e de práticas avaliativas, como também o funcionamento interno das escolas - os intramuros escolares.

Essa interferência externa cerceia a emergência de um modelo educativo autônomo e reforça as tendências predominantes no sistema escolar e na ideologia que o sustenta, produzindo ineficiência, má qualidade e desigualdade ao invés de contribuir para melhorar a qualidade dos aprendizados escolares na escola pública, sobretudo entre os setores menos favorecidos (Torres, 1996). O papel da escola reduz-se ao atendimento das necessidades mínimas de aprendizagem e ao provimento de um espaço de convivência e acolhimento social, relegando ao segundo plano - ou a plano algum -, sua função de prover os conhecimentos historicamente constituídos, integrantes do "conhecimento escolar".

Logo, o objetivo de levar os alunos a adquirirem o "conhecimento poderoso"(Young, 2007), ao qual eles não teriam acesso de outra forma ou em outro lugar, não é alcançado, e o desafio dos que pensam a escola pública reside justamente nisto: como assegurar os saberes públicos que apresentam um valor, independentemente de circunstâncias e interesses particulares, considerando ainda a coexistência das diferenças e a interação entre indivíduos de identidades culturais distintas, incorporando, nas práticas de ensino, as práticas socioculturais? (Libâneo, 2012). Aqui se acrescenta a questão norteadora deste artigo: como a escola pública pode atuar no enfrentamento das desigualdades?

Responder a essas questões implica discutir o currículo e a formação de professores, pois esses dois campos são fundamentais para se deslocar a ênfase do campo assistencial para os aspectos didáticopedagógicos da qualidade de ensino; ou seja, "os fatores intraescolares da aprendizagem escolar em que estão implicados os professores e pedagogos especialistas" (Libâneo, 2021, p. 25).

\section{No campo do currículo}

Em um sistema educacional polarizado em duas escolas - uma assentada no conhecimento, na aprendizagem, nas novas tecnologias e voltada à elite, e a outra voltada ao acolhimento social, à integração social e ao desenvolvimento das competências socioemocionais e para os pobres (Libâneo, 2012), romper a dominância desse dualismo torna-se um imperativo ético. Baseados na defesa da escola pública, laica e democrática, os fazedores e defensores da educação pública devem estar atentos para as possibilidades de intervenções disruptivas em resposta às demandas que a superação desse dualismo Ihes coloca, no sentido de empoderar a escola pública para que, de fato, ela participe do esforço de mudança social.

A promoção da igualdade social não ocorre de forma desvinculada do currículo escolar que, como já foi visto, expressa as relações de poder tanto na sociedade quanto na escola. Nesse esforço de mudança social, a escola deve se perguntar, assim como faz Young (2007, p. 1297): "Este currículo é um meio para que os alunos possam adquirir conhecimento poderoso?" Não o conhecimento que sustenta o modelo de currículo por resultados, implícito no currículo oficial, funcionando como um mecanismo de controle de escolas e professores e que responsabiliza esses últimos pelo sucesso ou insucesso dos alunos; tampouco o que se restringe ao conhecimento local e cotidiano que os alunos trazem para a escola, pois, como afirma Young (2007, p. 1297): 
Para crianças de lares desfavorecidos, a participação ativa na escola pode ser a única oportunidade de adquirirem conhecimento poderoso e serem capazes de caminhar, ao menos intelectualmente, para além de suas circunstâncias locais e particulares. Não há nenhuma utilidade para os alunos em se construir um currículo em torno da sua experiência, para que este currículo possa ser validado e, como resultado, deixá-los sempre na mesma condição.

O conhecimento poderoso ao qual todo estudante deve ter acesso diz respeito ao conjunto de conhecimentos especializados, relativos à ciência, à cultura, à filosofia, às novas tecnologias, dentre outros, não disponíveis de forma intencional e organizada fora da escola. Esses conhecimentos permitem chegar a generalizações e encontrar princípios de universalidade, possibilitando ao estudante a aquisição de parâmetros de compreensão do mundo que possam ir além do conhecimento prático do cotidiano (Young, 2007).

Isso não significa que a escola deva desconsiderar, no estabelecimento do currículo, a inclusão de conhecimentos relativos às experiências educativas locais, baseados em problemas cotidianos e que propiciem um ambiente em que os alunos se sintam acolhidos em suas singularidades e diversidade sociocultural. Não se trata também de, consoante ao pensamento neoliberal, estabelecer um currículo que conceba a escola como um lugar de aplicação de estratégias formativas com finalidades economicistas para o desenvolvimento de competências que, além de garantir um lugar no mercado de trabalho, também propicie formas de socialização para adaptação dos egressos da escola pública ao contexto da globalização competitiva (Libâneo; Freitas, 2018).

Ao contrário das visões alienantes de seleção, organização e oferta do que é considerado objeto de conhecimento escolar, sobretudo para os mais pobres, o currículo emancipador deve ser capaz de convergir à formação cultural e científica com as práticas socioculturais, nas quais manifestam-se as diferenças, os valores e as formas próprias de conhecimento local e cotidiano de diferentes grupos. Incluem-se nesses aspectos as questões étnico-raciais, de gênero e sexualidade, de classes sociais, de repertórios linguísticos e de crença e prática religiosa, que devem atravessar os conhecimentos estabelecidos no currículo de forma transversal, integrando o saber sistematizado que visa promover o desenvolvimento das capacidades cognitivas assegurando, pela diversidade, o direito à igualdade.

Na contramão de todo esse construto teórico progressista com respeito ao currículo, não se pode deixar de destacar as ingerências atuais nesse campo, encarnadas na Base Nacional Comum Curricular (Brasil, 2018). Esse documento, gestado em meio a disputas de poder, como é característico do currículo, foi criado para guiar gestores e professores quanto aos conteúdos mínimos a serem trabalhados na Educação Básica. Sua elaboração tem como princípio básico o desenvolvimento de habilidades e competências - com destaque especial às competências socioemocionais -, e é resultado da "parceria" entre o Ministério da Educação (MEC), organismos internacionais e organizações sociais privadas.

A Base Nacional Comum Curricular (BNCC) traz, para cada série/ano, as unidades temáticas, os objetos de conhecimento e as habilidades relativas às áreas do conhecimento, organizadas por meio de marcadores alfanuméricos que facilitam o controle por meio de testes e provas, além de cercear o trabalho do professor em sala de aula. Como esses conteúdos serão objeto de avaliação, gerando 
indicadores quantitativos de verificação do rendimento escolar, o professor se vê impedido de realizar um trabalho autônomo, adaptado à realidade sociocultural e regional de seus alunos e alunas.

A despeito desse currículo condescendente com os valores neoliberais, gestores e professores do sistema escolar podem criar alternativas por meio das brechas não preenchidas pela BNCC. A questão inicialmente proposta nesta seção, "Este currículo é um meio para que os alunos possam adquirir conhecimento poderoso?", poderá ser respondida positivamente quando professores e especialistas em educação, atuantes na escola pública, não se deixarem engessar pelo currículo, que não tem em si o poder de alterar a realidade objetiva. A primeira das dez competências estabelecidas pela BNCC, por exemplo, pode ser interpretada como uma síntese de todas as outras, e isso abre campo para uma ação emancipatória: "valorizar e utilizar os conhecimentos historicamente construídos sobre o mundo físico, social, cultural e digital para entender e explicar a realidade, continuar aprendendo e colaborar para a construção de uma sociedade justa, democrática e inclusiva" (Brasil, 2018, p. 9).

Logo, o decálogo, lido por olhos progressistas, poderá ensejar uma práxis docente que encarne o pressuposto existencial básico da escola, que deve ser o de buscar o êxito escolar de todos os alunos no processo de ensino e aprendizagem, incorporando crianças, adolescentes e jovens de distintas tradições familiares, identidades e comunidades, colocando em prática um currículo que, ao mesmo tempo em que contempla as diferenças - étnicas, sociais, culturais -, permite a congruência entre o universal e o particular (Libâneo, 2020). Esse currículo, suficientemente aberto para acolher a multiculturalidade do aluno da escola pública, também contempla os conhecimentos necessários para a construção da cidadania, pois transcende a realidade constatada, de modo a levar os alunos a olhá-la criticamente, a construir explicações e hipóteses para as problemáticas encontradas e a propor maneiras de superação com o apoio da mobilização do conhecimento poderoso.

\section{No campo da formação de professores}

No ano de 2015, o Brasil avançou muito, por meio da CNE/CP no 2, no que tange às Diretrizes Curriculares Nacionais para a Formação de Professores da Educação Básica. De caráter progressista, essas diretrizes resultaram de um trabalho colaborativo, com engajamento do próprio Conselho Nacional de Educação (CNE) e de vários atores coletivos governamentais e não governamentais, profissionais da educação, entidades acadêmicas e sindicais, movimentos sociais etc. As Diretrizes Curriculares Nacionais (DCN) explicitam claramente os princípios formativos que visam à necessária articulação teoria-prática, defendem uma sólida base teórico-pedagógica interdisciplinar, reconhecem a especificidade da formação docente, preveem a articulação entre a formação inicial e continuada entre as instituições formadoras e as instituições de Educação Básica, defendem a valorização do profissional da educação e a melhoria de suas condições de trabalho, dentre outros aspectos.

No entanto, nesse mesmo ano, o MEC iniciou o processo de reforma curricular dos cursos de formação de professores, atropelando as diretrizes recentemente propostas. Subordinadas à lógica de formação por competências subjacente à BNCC, as "novas diretrizes" vão dando corpo a uma concepção restrita e instrumental de docência, articulada a uma prática que condiciona a segmentação de conteúdos e metodologias ao fazer a alteração dos eixos formativos de forma prescritiva e pelo caráter impositivo, reducionista e aligeirado dos processos formativos. Além disso, chama especial atenção pelos impactos 
danosos da lógica que orienta a proposta da carreira docente, fundamentada em avaliações e certificação para o ingresso e progressão na carreira.

Essa revisão expressa não apenas a intenção de desmonte dos cursos de formação de professores, como também o aprofundamento do processo de desprofissionalização da carreira docente. Assumiuse uma visão "praticista" da docência, que afrontou a autonomia das universidades ao desconsiderar os projetos curriculares dos cursos e padronizá-los, alinhando-os à BNCC. Para o sistema, era necessário padronizar a formação e consequentemente aumentar o controle sobre o trabalho docente. Esse processo de revisão culminou com a publicação da Resolução CNE/CP n 2 de 20 de dezembro de 2019, que estabeleceu a Base Nacional Comum da Formação de Professores (BNCFP), preterindo as DCN de 2015 que, ao contrário da atual, buscavam, em seu cerne, vincular-se às demandas formativas de estudantes e professores e da realidade concreta da escola pública brasileira, considerando a pluralidade de ideias e concepções pedagógicas, bem como os avanços do conhecimento no campo educacional.

A citada resolução de 2019, nos Art. $2^{\circ}$ e 30, predefine o "currículo oculto" que subsidia a BNCFP ao dizer que:

Art. $2^{\circ} \mathrm{A}$ formação docente pressupõe o desenvolvimento, pelo licenciando, das competências gerais previstas na BNCC-Educação Básica, bem como das aprendizagens essenciais a serem garantidas aos estudantes, quanto aos aspectos intelectual, físico, cultural, social e emocional de sua formação [...].

Art. $3^{\circ}$ Com base nos mesmos princípios das competências gerais estabelecidas pela BNCC, é requerido do licenciando o desenvolvimento das correspondentes competências gerais docentes (Brasil, 2019, p. 2).

Logo, se determinou a partir da reforma que os cursos de formação devem reproduzir, de forma especular, os conteúdos a serem ensinados pelos futuros professores em seu campo de atuação na Educação Básica, os quais também terão que desenvolver, durante a licenciatura, as mesmas competências previstas para seus futuros alunos. Assume-se uma concepção de docência instrumental e, portanto, restrita, além de simular articular-se à prática sem configurar-se como práxis de fato.

A despeito do aparelhamento em curso da educação brasileira - tanto da Básica quanto da Superior -, as instituições responsáveis pela formação de professores no Brasil que, de fato, têm um compromisso com a construção de uma sociedade mais justa e anseiam contribuir para a formação de sujeitos autônomos e protagonistas de processos de mudanças, podem encontrar formas de agir mesmo no meio das contradições. Ao mirar a totalidade, podem identificar brechas emancipatórias para orientar a luta em uma direção mais ampla. Devem se perguntar sobre qual seria o lugar da formação docente e do engajamento que a formação deve ter na superação da desigualdade.

Em seu Art. 70, a CNE/CP no 2/2019, por exemplo, nos incisos III, V e VI, reconhece "o direito de aprender dos licenciandos e compromisso com a aprendizagem como valor em si mesmo" (Brasil, 2019, p. 4), o que dá margem a que não se restrinja os cursos de formação ao desenvolvimento de competências previamente desenhadas pelo mercado de trabalho, mas destacar as aprendizagens relevantes para o futuro professor que deverá lidar com a diversidade em todos os seus aspectos ao lecionar na escola pública. Afirma, ainda, "atribuição de valor social à escola e à profissão docente de 
modo contínuo, consistente e coerente com todas as experiências de aprendizagem dos professores em formação" e, no inciso XIV, "a adoção de uma perspectiva intercultural de valorização da história, da cultura e das artes nacionais, bem como das contribuições das etnias que constituem a nacionalidade brasileira" (Brasil, 2019, p. 4). Ou seja, a escola e o profissional docente tornam-se indissociáveis no papel social a cumprir, o de garantir a aprendizagem de todos os alunos, de qualquer nível social, tradição cultural ou grupo étnico. As escolas de formação, portanto, devem incluir os conhecimentos relacionados ao rico arcabouço cultural, histórico e artístico em seus processos formativos, de modo a preparar os futuros docentes para adotarem abordagens de ensino que levem isso em consideração.

O "pluralismo de ideias e de concepções pedagógicas" está previsto no inciso X do Art. 6 (Brasil, 2019 , p. 3) como princípio relevante e dá azo para uma formação que não se restrinja a concepções anacrônicas, a visões conservadoras do conhecimento e a práticas engessadas por uma concepção tecnicista e instrumental do papel do professor. A multiplicidade cultural flagrada nas salas de aula e os distintos contextos e situações de ensino-aprendizagem que envolvem a docência demandam diferentes formas de promoção da aprendizagem.

Essas "liberdades" proclamadas pela resolução, como outras que ela expressa, devem resultar em ações, por parte das instituições formadoras, que contribuam para a construção da autonomia e da emancipação do próprio licenciando, mobilizando-o em direção a uma práxis capaz de alterar significativamente as concepções e práticas nas escolas onde irá atuar, afetando tanto os estudantes quanto seus pares - os demais professores. Esses, à medida que se veem como agentes sociais, vão criando condições de se comprometerem com a qualidade da formação de seus alunos, tanto do ponto de vista do domínio dos objetos de conhecimento científicos e culturais, quanto da formação de cidadãos críticos, reflexivos e protagonistas de processos de mudanças, despertando neles o desejo de se engajarem no esforço de superação da desigualdade.

\section{Considerações Finais}

Este texto teve início com uma breve retrospectiva da história da escola pública, destacando que desde seu início, numa Europa que se modernizava, duas marcas significativas se firmaram: sua forte participação na consolidação de uma sociedade assentada em um novo modo organizador da vida econômica, política e social, assegurando uma necessária homogeneização cultural, e sua constituição como a porta através da qual os pobres são incorporados à vida civilizada e, ao mesmo tempo, assegurar a necessária diferenciação dos sujeitos numa sociedade de classes. No Brasil essas marcas se firmaram e foram ganhando as cores próprias de uma sociedade marcada pelas desigualdades decorrentes da herança colonial-escravocrata-aristocrática, o que faz da escola pública contemporânea objeto de disputas decorrentes de projetos políticos antagônicos que a entendem como direito de todos e obrigação do Estado ou como mais um espaço de comércio a serviço da concentração da riqueza.

Firmou-se a compreensão de que a desigualdade se constitui como elemento estruturante da sociedade brasileira, ganhando vida no seio das instituições sociais e das relações políticas concretas, manifestando-se de diferentes formas. O esforço por entendê-las no campo educacional - cerne das reflexões aqui empreendidas -, leva ao encontro das políticas educacionais marcadamente 
compromissadas com interesses político-econômicos engendrados internacionalmente. Assim, tem-se hoje um dualismo no tipo de ensino disponibilizado às crianças e jovens brasileiros, que contribui para a existência de acessos diferentes à estrutura de oportunidades e aos direitos.

Nessa perspectiva, a desigualdade escolar se apresenta como o conjunto de condições subjetivas e objetivas que condicionam, em última instância, a manutenção das posições na ordem imanente de sua reprodução. Logo, as vantagens sociais que advêm da desigualdade, além de se acumularem ao longo da vida, são vistas como conquistas derivadas do esforço individual ou do talento de cada um, conferindo legitimidade a um quadro de assimetria social historicamente produzido.

Por fim, adentrou-se o campo do currículo e da formação de professores por entendê-los como lugares político-epistemológicos onde se travam objetivamente as disputas entre projetos educativos, sejam eles voltados para a busca da emancipação ou da reprodução social sob a forma ideológica neoliberal. À luz desse entendimento pode-se dizer que, com seus mecanismos de seleção socialmente legitimados, a escola dual estimula uma exclusão continuada dos desfavorecidos das melhores posições, reforçando sentidos meritocráticos ou de resultados que mostram sua face como hierarquia frente ao acesso aos direitos e às relações com o saber.

Embora estruturado pelos sentidos acima referidos, o currículo escolar se apresenta com roupagem "humanista" para adequar o sujeito às novas exigências de um mercado instável e desregulamentado que requer um sujeito dócil e crédulo de que o mérito próprio é o único responsável por seu sucesso ou seu fracasso. Por exemplo, no campo da formação de professores, o MEC suprimiu um conjunto de diretrizes dos cursos de formação, anteriormente construídas com ampla participação, substituindo-as por outras irmanadas ao espírito orientador da BNCC, centrado na formação por competências. Instaurase, assim, uma concepção restrita e instrumental de docência.

Por conseguinte, vive-se um processo de desarticulação das experiências exitosas duramente construídas nesse campo e o aprofundamento de uma perspectiva praticista de docência em que a teoria é desqualificada. Ao mesmo tempo em que essas novas diretrizes provocam o aprofundamento da erosão da já tão difícil carreira docente, ainda incrementam o processo de desprofissionalização. 0 consequente apagamento da "consciência de classe", que expressa os lugares diferenciais ocupados no espaço social, serve aos propósitos alienantes das políticas neoliberais. Com isso, cada vez mais, reiterase, no Brasil, o caráter passivo do papel da educação, sobretudo quando observada da perspectiva da macroestrutura, pois a legislação que embasa as políticas públicas nesse campo caminha no sentido de adaptar-se às mudanças já em curso, quando deveria realizá-las e, assim, empoderar a escola pública.

A despeito dessas ingerências resultantes da hegemonia neoliberal no currículo e nos cursos de formação de professores, os diferentes atores envolvidos com a educação escolar pública podem atuar nas brechas não preenchidas pela legislação educacional, deixando-se guiar, em suas ações, pelo objetivo de levar os estudantes a adquirir conhecimento poderoso. A BNCC e a BNCFP, interpretadas pelos olhos progressistas de gestores, professores e instituições formadoras, podem inspirar uma práxis docente que persiga o êxito escolar de todos os alunos no processo de ensino e aprendizagem, além de promover a construção da autonomia e da emancipação do futuro professor. Esse, então, consciente de sua função social, poderá inspirar em seus alunos e alunas, por meio de sua práxis, o desejo de superação das desigualdades. 


\section{Colaboradores}

Todos os autores contribuíram igualmente para a concepção do artigo, seleção da bibliografia, produção das análises/conteúdos, revisão e aprovação da versão final.

\section{Referências}

Bourdieu, P. A escola conservadora: as desigualdades frente à escola e à cultura. In: Catani, A.; Nogueira, M. A. (org.). Escritos de Educação. 9. ed. Petrópolis: Vozes, 2007. p. 39-64.

Bourdieu, P.; Champagne, P. Os excluídos do interior. In: Catani, A.; Nogueira, M. A. (org.). Escritos de Educação. 9. ed. Petrópolis: Vozes, 2007. p. 217- 228.

Bourdieu, P.; Passeron, J. A reprodução: elementos para uma teoria do sistema de ensino. 6. ed. Petrópolis: Vozes, 2013.

Brasil. Ministério da Educação. Base Nacional Comum Curricular. Brasília: Ministério da Educação, 2018. Disponível em: http:// basenacionalcomum.mec.gov.br/images/BNCC_El_EF_110518_versaofinal_site.pdf Acesso em: 19 mar. 2021.

Brasil. Ministério da Educação. Resolução CNE/CP no 2, de 20 de dezembro de 2019. Define as Diretrizes Curriculares Nacionais para a Formação Inicial de Professores para a Educação Básica e institui a Base Nacional Comum para a Formação Inicial de Professores da Educação Básica. Brasília: Ministério da Educação, 2019. Disponível em: http://portal.mec.gov.br/docman/ dezembro-2019-pdf/135951-rcp002-19/file. Acesso em 20 mar. 2021.

Cambi, F. História da pedagogia. São Paulo: Editora UNESP, 1999.

Carvalho, M. M. C. A produção do vazio: considerações sobre a memória das lutas pela escola pública no Brasil. In: Boto, C. et al. (org.). A escola pública em crise: inflexões, apagamentos e desafios. São Paulo: FEUSP, 2020. p. 109-102.

Coleman, J. O conceito de igualdade de oportunidades educacionais. Educação, Sociedade \& Culturas, n. 34, p. 137-155, 2011.

Crahay, M. Como a escola pode ser mais justa e mais eficaz? Cadernos Cenpec, v.3, n. 1, p. 9-40, 2013.

Dubet, F. Democratização escolar e justiça da escola. Educação, v. 33, n. 3, p. 381-394, 2008.

Dubet, F. O que é uma escola justa? Cadernos de Pesquisa, v. 34, n. 123, p. 539-555, 2004.

Fernandes, F. Educação e sociedade no Brasil. São Paulo: Dominus, 1966.

Hamilton, D. Notas de lugar nenhum: sobre os primórdios da escolarização moderna. Revista Brasileira de História da Educação, v. 1, n. 1, p. 45-73, 2001.

Instituto Brasileiro de Geografia e Estatística. Pesquisa Nacional por Amostragem de Domicílios Contínua: Educação 2019. Brasília, IBGE, 2019. Disponível em: https://biblioteca.ibge.gov.br/visualizacao/livros/liv101736_informativo.pdf. Acesso em: 10 jul. 2021.

Libâneo, J. C. Currículo de resultados, atenção à diversidade, ensino para o desenvolvimento humano: contribuição ao debate sobre a escola justa. BOTO, C. et al. (org.). A escola pública em crise: inflexões, apagamentos e desafios. São Paulo: FEUSP, 2020. p. 41-67.

Libâneo, J. C. O dualismo perverso da escola pública brasileira: escola do conhecimento para os ricos, escola do acolhimento social para os pobres. Educação e Pesquisa, v. 38, n. 1, p. 13-28, 2012.

Libâneo, J. C. Políticas educacionais neoliberais e escola: uma qualidade de educação restrita e restritiva. In: Libâneo, J. C.; Freitas, R. A. M. M. (org.). Políticas educacionais neoliberais e escola pública: uma qualidade restrita de educação escolar. Goiânia: Espaço Acadêmico, 2018. p. 44-87.

Libâneo, J. C.; Freitas, R. A. M. M. A pesquisa: repercussões de políticas educacionais na escola e na sala de aula. In: Libâneo, J. C.; Freitas, R. A. M. M. (org.). Políticas educacionais neoliberais e escola pública: uma qualidade restrita de educação escolar. Goiânia: Espaço Acadêmico, 2018. p. 22-43.

Lombardi, J. C.; Colares, A. A. Escola pública, projeto civilizatório burguês versus práxis emancipadoras. Revista USP, n. 127, p. $11-26,2020$

Pinto, U. A. Pedagogia e pedagogos escolares. 2006. 184 f. Tese (Doutorado em Educação) - Universidade de São Paulo, São Paulo, 2006.

Ribeiro, D. Sobre o óbvio. Lutas Anticapital: Marília, 2019. 
Torres, R. M. Melhorar a qualidade da educação básica? As estratégias do Banco Mundial. In: Tommasi, L.; Warde, M. J.; Haddad, S. (org.). O Banco Mundial e as políticas educacionais. São Paulo: Cortez Editora, 1996. p. 125-193.

Veiga, C. G. A escolarização como projeto de civilização. Revista Brasileira de Educação, n. 21, p. 90-103, 2002.

Young, M. Para que servem as escolas? Educação \& Sociedade, v. 28, n. 101, p. 1287-1302, 2007.

Recebido em 30/3/2021, versão final em 24/8/2021 e aprovado em 9/9/2021. 